\title{
Possibilidades do Ensino Médio Integrado diante do financiamento público da educação
}

Ramon de Oliveira

Universidade Federal de Pernambuco

\section{Resumo}

Esse trabalho, tendo como referência a trajetória do Ensino Médio brasileiro nos últimos 16 anos, destaca os limites do financiamento público à edificação do Ensino Médio Integrado. Apoiando-se em uma literatura sobre o Ensino Médio e a Educação Profissional que defende a escola unitária, analisam-se dados concernentes à última etapa da Educação Básica, particularmente das escolas das redes estaduais. Argumenta-se que a intervenção do governo federal brasileiro no financiamento da Educação é um grande obstáculo à efetivação do Ensino Médio Integrado, uma vez que, independentemente do viés ideológico ou do pertencimento partidário daquele que dirige a nação, não se tem colocado essa etapa da Educação Básica como prioridade no raio do financiamento estatal. Registra-se a hegemonia das escolas estaduais na oferta do Ensino Médio e o aumento nas quais há a integração entre o Ensino Médio e a Educação Profissional. Por último, afirma-se que embora o FUNDEB represente uma ação que contemple o Ensino Médio como alvo do financiamento público dos estados, não gerará recursos suficientes para garantir o financiamento da última etapa da Educação Básica, principalmente na modalidade integrada à Educação Profissional. Conclui-se defendendo uma modificação do papel do governo federal no financiamento do Ensino Médio, de forma a garantir que a articulação entre a formação técnica e a formação geral possa universalizar-se e com melhor qualidade nas escolas estaduais.

\section{Palavras-chave}

Ensino Médio Integrado - Financiamento da Educação - Ensino Técnico.

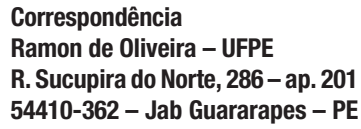




\title{
Possibilities of integrated secondary schooling considering the public funding of education
}

\author{
Ramon de Oliveira \\ Universidade Federal de Pernambuco
}

\begin{abstract}
Taking as its reference the trajectory of secondary education in Brazil during the last 16 years, this work focuses on the impacts of limitations in public funding to the construction of an integrated secondary school system. Drawing from a literature on secondary and professional education that defends a unitary school, the article analyzes data related to the last stage of basic education, particularly in schools of the state system. It argues that the intervention of the Brazilian federal government in the funding of education constitutes a huge obstacle to the implementation of an integrated secondary school, since regardless of any ideological bias or party allegiance on the part of those governing the nation, this stage of education has not been considered as a priority for state funding. The work observes the hegemony of state schools in the offer of secondary education, and the increase in the number of schools in which there is integration between secondary schooling and professional education. Lastly, the text notes that, although FUNDEB represents an initiative that places secondary education as a candidate for state funding, it will not produce enough resources to guarantee the funding of the last stage of basic education, especially in a modality integrated to professional training. It concludes by defending a modification of the role played by the federal government in the funding of secondary education, so as to guarantee that the articulation between technical training and general education can be universalized, and with better quality, throughout state schools.
\end{abstract}

\section{Keywords}

Integrated Secondary Education - Funding of Education - Technical Training.

Contact:

Ramon de Oliveira

R. Sucupira do Norte, 286 - ap. 201

54410-362 - Jab Guararapes - PE

e-mail: ramono@elogica.com.br 
Ao voltar-se a atenção para o Ensino Médio, especificamente quando se pensa sobre a sua função social, ainda coloca-se em discussão a possibilidade de conjugar-se, nesse nível de ensino, a preparação para o trabalho e a formação para a continuidade dos estudos. Essa polêmica, fortalecida com a reforma da Educação Profissional (Decreto 2208/1997), reafirmase como discussão importante, na medida em que o atual governo revogou o decreto anteriormente citado e possibilitou a oferta do Ensino Médio Integrado - EMI (Decreto 5154/2004).

Destacar a importância da articulação entre a formação geral e a formação profissional ainda se coloca como pedagógica e politicamente importante, uma vez que deve haver e vem existindo uma contínua e ininterrupta preocupação por parte daqueles que pesquisam na área de Trabalho e Educação e/ou Ensino Médio de reafirmar o quanto o processo de formação profissional não pode resumir-se apenas à apropriação de saberes práticos e úteis ao mercado de trabalho. Cada vez mais, a luta política por um Ensino Médio que objetive a formação "integral" dos educandos impõe-se como necessária e consequente.

Mesmo questionando o quanto o Ministério da Educação estava preocupado, ao conceber o Decreto 5154/2004, em concretizar um projeto de Educação Profissional e de Ensino Médio que fizesse jus ao conjunto de discussões e debates produzidos nos últimos anos, não podemos deixar de reconhecer que passamos a vivenciar a possibilidade de avançarmos no processo de construção de um novo projeto para o Ensino Médio. Como ressaltaram Frigotto et al. (2005), a direção da legislação educacional, e nesta se enquadra o novo decreto, depende das forças que estão disputando o projeto educacional para a sociedade brasileira. Nesse sentido, a integração, da mesma forma que corre riscos de pouco materializar-se, contraditoriamente, abre novas possibilidades para o Ensino Médio.

Por mais que o novo decreto abra a possibilidade da retomada do EMI, esse modelo ainda não se configura como o projeto de educação para classe que vive do trabalho. 0 EMl "conquanto seja uma condição social e historicamente necessária para a construção do ensino médio unitário e politécnico, não se confunde com ele..." (Frigotto et al., 2005, p. 15).

Reconhecer essa distância entre o EMl e a escola de caráter politécnico implica buscar, no âmbito dos limites da materialidade burguesa, a constituição de um projeto educativo que, ao emergir no imaginário coletivo, possa solidificar práticas coletivas capazes de levar o poder público a garantir que esse ensino seja provedor de uma formação que contribua para a emancipação da classe que vive do trabalho.

Nesse sentido, a questão que ora se coloca diz respeito não apenas a uma concepção de formação profissional e de nível médio a ser implementada, mas fundamentalmente à disponibilidade de recursos para que tal projeto possa tornar-se realidade. Ou seja, a luta por uma escola que abrigue a formação técnica em articulação com o Ensino Médio impõe o repensar da infraestrutura, do currículo, da valorização dos profissionais da Educação etc. 0 que torna obrigatório o repensar do financiamento público desse nível de ensino.

Considerando ser a oferta pública do Ensino Médio majoritariamente promovida pelas escolas da rede estadual, convém analisar a possibilidade de concretização do EMI, dando atenção especial ao que vem ocorrendo nas escolas estaduais, pois elas abrigam e abrigarão a maioria dos aspirantes a uma certificação profissional ao final da Educação Básica.

Nessa perspectiva, esse trabalho, tendo como referência a trajetória do Ensino Médio brasileiro nos últimos 16 anos ${ }^{1}$, destaca os limites do financiamento público, para edificar, de fato, o EMI nas escolas que atendem aos sujeitos oriundos da classe trabalhadora, pressupondo que a luta pelo financiamento do EMI deve ser vista não apenas como um movimen-

1. 0 intervalo de 16 anos foi definido em função da disponibilidade de dados referentes ao Ensino Médio. 0 movimento de crescimento mais acelerado de suas matrículas teve início um pouco antes. 
to em defesa da escola pública de qualidade, mas como uma ação concreta, visando à constituição de uma escola unitária.

\section{- Ensino Médio Integrado:} perspectivas de uma educação integral

A história do Ensino Médio brasileiro confunde-se com o debate sobre a sua identidade e a dificuldade e/ou o descompromisso do Estado de torná-lo acessível a um contingente mais expressivo da população.

A tentativa da Lei 5692/71 de garantir a esse nível de ensino uma identidade que pudesse, ao mesmo tempo, contribuir para a inserção precoce de jovens no mercado de trabalho e garantir a sua chegada à universidade mostrouse, politicamente, excludente. Nem garantiu uma formação técnica satisfatória nem permitiu a aprendizagem satisfatória dos chamados conteúdos gerais, fundamentais no momento de realização do vestibular ${ }^{2}$.

A tentativa de universalizar a articulação entre a formação geral e a formação técnica não conseguiu superar a dualidade histórica que persegue o Ensino Médio, pois as escolas não se estruturaram a partir de um novo princípio educativo, no qual o pensar e o fazer fossem considerados expressões de um único saber constituinte da identidade humana. Como destacou Kuenzer (2002), essa dualidade, ao decorrer das contradições de classes existente, não pode encontrar sua superação no âmbito do projeto político-pedagógico escolar.

Assim é que já se tem demonstrado ser a dualidade estrutural a categoria explicativa da constituição do Ensino Médio e Profissional no Brasil, já que, desde o surgimento da primeira iniciativa estatal nessa área até o presente, sempre se constituíram duas redes - uma profissional e outra de educação geral - para atender às necessidades socialmente definidas pela divisão social e técnica do trabalho. (p. 26)
A superação dessa dualidade histórica foi vislumbrada no plano legal quando das discussões da LDB em vigor (Frigotto et al., 2005). Entretanto, após a derrota da proposta progressista, o que temos presenciado é um movimento contínuo por parte das forças mais conservadoras de fazer com que a formação profissional de nível técnico restrinja-se ao atendimento imediato do mercado. A reforma da Educação Profissional implementada por meio do Decreto 2208/97 conseguiu materializar o desejado pelo atores nacionais comprometidos com a ideologia do capital (Cunha, 2002) e, ao mesmo tempo, expressou a materialização das diretrizes das agências internacionais (Oliveira, 2006).

0 Ensino Médio deve ter uma relação direta com o que ocorre no mundo do trabalho, entretanto essa relação não pode ser confundida com uma submissão ao imediatismo preconizado pelo mercado de trabalho. Como destacou Frigotto (2005), trata-se de uma relação imediata e estruturada a partir da natureza ontocriativa do trabalho.

0 EMl não deve ser palco para o desenvolvimento de competências ou de habilidades preconizadas no discurso empresarial. Essa etapa da Educação Básica não pode e não deve estar voltada para o aumento da produtividade tão em voga no momento atual. 0 EMl deve ser considerado um espaço/tempo de superação, no plano formativo, da fragmentação imposta pela divisão social do trabalho.

A ideia de formação integrada sugere superar o ser humano dividido historicamente pela divisão social do trabalho entre a ação de executar e a ação de pensar, dirigir ou planejar. Trata-se de superar a redução da preparação para o trabalho ao seu aspecto operacional, simplificado, escoimado dos conhecimentos que estão na sua gênese científico-tecnológica e na sua apropriação histórico-social. Como formação humana, o que se busca é garantir

2. A análise de textos que discutiram a Lei 5.692/71, bem como 0 estado da arte do Ensino Médio técnico, considerando a produção dos anos 1980 e 1990, podem ser encontrados em Frigotto e Ciavatta (2006). 
ao adolescente, ao jovem e ao adulto trabalhador o direito a uma formação completa para leitura do mundo e para atuação como pertencente a um país, integrado dignamente à sua sociedade política. Formação que, nesse sentido, supõe a compreensão das relações sociais subjacentes a todos os fenômenos. (Ciavatta, 2005, p. 85)

Perseguir esse perfil para o EMl está vinculado à construção de um projeto de sociedade contrário ao instituído pelo capital. Como destacou essa autora:

0 primeiro pressuposto da formação integrada é a existência de um projeto de sociedade no qual, ao mesmo tempo, se enfrente os problemas da realidade brasileira, visando a superação do dualismo de classes e as diversas instâncias responsáveis pela educação (governo federal, secretarias de Educação, direção das escolas e professores) manifestem a vontade política de romper com a redução da formação à simples preparação para o mercado de trabalho. (p. 98)

A questão do EMI, portanto, não está desarticulada da luta política. 0 objetivo da formação integral dos educando é, antes de tudo, romper com a fragmentação que historicamente tem sido imposta aos estudantes oriundos da classe trabalhadora. É, dessa forma,

[...] disponibilizar aos jovens que vivem do trabalho a nova síntese entre o geral e o particular, entre o lógico e o histórico, entre a teoria e a prática, entre o conhecimento, o trabalho e a cultura. (Kuenzer, 2002, p. 43-44)

0 caráter dual que predominou na história do Ensino Médio brasileiro decorre do projeto excludente que as classes economicamente dominantes conseguiram tornar vitorioso. Mesmo quando observamos um crescimento do número de matrículas nesse nível de ensino, não é desconhecido o quanto esse fato está articula- do à diminuição da sua qualidade, provocando que os jovens brasileiros apresentem um nivel de aprendizagem bem abaixo do aceitável.

Contraditoriamente, mas na mesma lógica do processo de exclusão da classe que vive do trabalho, a história do Ensino Médio é a história da inclusão daqueles que puderam e podem, em virtude de uma condição de classe distinta, apropriar-se da produção material e não material.

É sempre bom lembrar que o Ensino Médio no Brasil tem exercido, entre outras, a função de referendar a inclusão dos incluídos, justificada pelos resultados escolares. $\mathrm{Na}$ verdade, os incluídos vivenciam um conjunto de experiências sociais e culturais que lhes assegura larga vantagem na relação com o conhecimento sistematizado, isso sem falar nas condições materiais favoráveis ao estabelecimento dessa relação. Assim é que, não por coincidência, os que permanecem na escola são também os que melhor se comunicam, têm melhor aparência, dominam mais conhecimentos e apresentam condutas mais adequadas ao disciplinamento exigido pela vida escolar, produtiva e social. (Kuenzer, 2002, p. 43)

Superar esse caráter dualista e excludente do Ensino Médio, tendo como referência a construção da escola unitária, é estar atento ao fato de que esse projeto só poderá ser efetivado fora dos limites da sociabilidade capitalista. Entretanto, o momento presente é fundamental para podermos instituir práticas e vitórias que possam ir aos poucos edificando pilares sólidos para um novo projeto de formação humana.

Nesse sentido, é necessário o desencadeamento de ações criativas, visando a uma escola que propicie:

[...] as necessárias mediações para que os menos favorecidos estejam em condições de identificar, compreender e buscar suprir, ao longo de sua vida, suas necessidades 
com relação à participação na produção científica, tecnológica e cultural. (Kuenzer, 2002, p. 43)

Resistir também assume a forma de se colocar ao lado daqueles que vivenciam a Educação Profissional de nível médio no seu dia a dia e que vinham avançando na construção de um projeto de formação profissional pautado em outra perspectiva de formação humana que aquela objetivada pelo capital. Nesse sentido, não se pode esquecer que os trabalhadores da Educação vinculados às instituições federais de educação tecnológica foram pegos de surpresa pelo autoritarismo do governo Fernando Henrique e viram ser totalmente descartado o acúmulo de discussões desenvolvidas ao longo da década de 1990, no sentido de propor um projeto de educação profissional que superasse o modelo de formação até então vigente. Nesse sentido, vale a pena registrar o que o Sindicato Nacional dos Servidores Federais de Educação Básica e Profissional - SINASEFE - apontou como proposta de Educação Profissional e sua integração ao Ensino Médio.

A ação formativa que interessa às classes trabalhadoras é aquela que lhes confere o atributo do livre pensar e o refletir, permitindo que abstraiam, analisem, sintetizem e desenvolvam a sua cultura em comunicação, possibilitando sua autonomia e sua consciência individual e coletiva. Esta pressupõe uma sólida formação básica e uma estreita articulação entre a cultura geral e tecnológica. Trabalhar a educação tecnológica integrada à formação geral é a única maneira de modificar substancialmente o estatuto dos conhecimentos técnicos e a eles agregados. Tanto a formação inicial como a continuada deverão orientar-se pelos mesmos princípios, pois a educação continuada do trabalhador e o reingresso no mundo do trabalho exigem formação integral do trabalhador. (SINASEFE, 2004, p. 2)

$\mathrm{Na}$ perspectiva de fomentar essas práticas, discutiremos agora o processo de cresci- mento do Ensino Médio nos últimos 15 anos, procurando evidenciar que um dos maiores limites para a efetivação da formação integrada resulta da politica de financiamento instituída pelo Estado brasileiro.

A forma como o Estado vem se responsabilizando pelo Ensino Médio, tanto no que diz respeito à concepção quanto ao financiamento, são obstáculos à efetivação de um projeto educativo no qual seja garantido não só o acesso aos saberes indispensáveis à formação técnica stricto sensu, mas também à apropriação de conhecimentos e à vivência de práticas que contribuam para a atuação na sociedade.

Nossa análise dos limites impostos para efetivação de um Ensino Médio de qualidade segue a mesma compreensão expressa por Kuenzer (2002) quando ela afirma que a democratização do Ensino Médio não é só uma questão de ampliação de vagas,

[...] exige espaços físicos adequados, bibliotecas, laboratórios, equipamentos e, principalmente, professores concursados e capacitados. Sem essas precondições, discutir um novo modelo, pura e simplesmente, não tem sentido. (p. 35)

\section{Ensino médio integrado: dados de realidade}

0 Ensino Médio, embora esteja longe de ter garantida sua universalização, dá sinais expressivos de como as políticas efetuadas pelos governos estaduais ampliaram a sua oferta. Em 1992, havia no Brasil um pouco mais de 4,1 milhões de matrículas nesse nível de ensino e dezesseis anos depois, considerando as matrículas registradas na Educação Profissional integrada ao Ensino Médio, atingiu-se o total de mais de 8 milhões, ou seja, um crescimento de 104\%, como pode ser constatado na Tabela $1^{3}$.

3. A partir de 2004, está havendo uma diminuição de matrículas no Ensino Médio. Naquele ano, comparando-se ao de 1992, houve um crescimento de matrículas na ordem de $123 \%$. 
Tabela 1: Evolução das matrículas do Ensino Médio por dependência administrativa.

\begin{tabular}{|l|c|c|c|c|c|c|c|c|}
\hline & 1992 & $\mathbf{1 9 9 4}$ & $\mathbf{1 9 9 6}$ & $\mathbf{1 9 9 8}$ & $\mathbf{2 0 0 0}$ & $\mathbf{2 0 0 2}$ & $\mathbf{2 0 0 4}$ & $\mathbf{2 0 0 7 ^ { * }}$ \\
\hline MATRIC. & 4.104 .643 & 4.992 .552 & 5.739 .077 & 6.968 .531 & 8.192 .948 & 8.710 .584 & 9.169 .357 & 8.369 .369 \\
\hline R. ESTAD. & 2.836 .676 & 3.522 .970 & 4.137 .324 & 5.301 .475 & 6.662 .727 & 7.297 .179 & 7.800 .983 & 7.239 .523 \\
\hline R. MUNI. & 223.855 & 327.803 & 312.143 & 317.488 & 264.459 & 210.631 & 189.331 & 163.779 \\
\hline R. FED. & 98.584 & 100.007 & 113.091 & 122.927 & 112.343 & 79.874 & 67.652 & 68.999 \\
\hline R. PRIV. & 945.528 & 1.041 .772 & 1.176 .519 & 1.226 .641 & 1.153 .419 & 1.122 .900 & 1.111 .391 & 897.068 \\
\hline
\end{tabular}
^Em 2007, computam-se para o Ensino Médio as matrículas da educação profissional, ofertada de forma integrada.
Caso esta fosse considerada, concomitante ou sequencial ao Ensino Médio, teríamos um incremento de 693.610 matrículas.
Fonte: Montagem própria a partir do Censo Escolar - diversos anos. Disponível em <www.inep.gov.br>.

Se o Ensino Médio teve, entre os anos de 1992 e 2007, um expressivo crescimento, as matrículas nas redes estaduais são as principais responsáveis por esse crescimento, evidenciando que qualquer análise desse nível de ensino ministrado na rede pública deve se basear nos dados das escolas da rede estadual. Elas são responsáveis por um quantitativo de $86,5 \%$ de todas as matrículas em nível nacional e $97 \%$ da rede pública. Nesse sentido, a discussão sobre a possibilidade do EMI deve considerar, fundamentalmente, o financiamento das redes estaduais de ensino.

Quando se analisa a oferta de Educação Profissional de nível técnico no Brasil, percebese o quanto ela está privatizada. Em 2007, das 693.610 matrículas realizadas em todo o país, 371.966 foram da iniciativa privada. Mais expressivo é o percentual da presença da iniciativa privada entre as instituições que ofertam a Educação Profissional de nível técnico: 66\%. Evidencia-se que o processo de privatização desse tipo de educação, recomendado pelas agências internacionais de financiamento (Oliveira, 2006), realmente conseguiu materializarse. Especificamente sobre a oferta de Educação Profissional técnica de nível médio das redes estaduais, em 2007, o total de matrículas chegou a 215.252, para um total de 792 escolas envolvidas nessa oferta.

É importante registrar que o número de escolas das redes estaduais que passaram o ofertar a Educação Profissional vem crescendo nos últimos três anos. De acordo com os dados do INEP, em 2003, tínhamos 553; em 2004, 602; em 2005, 659; e chegamos em 2007, último ano com dados disponíveis, a 727 estabelecimentos ofertando esse tipo de educação, integrada, concomitante ou sequencial ao Ensino Médio. Tal crescimento parece evidenciar que algumas redes estaduais estimularam-se, pela possibilidade aberta com o Decreto 5154/2004, a promover a oferta de Educação Profissional, seja na forma integrada, concomitante ou subsequente. De acordo com o decreto 5154 de 2004, que revogou o Decreto 2208/97 e passou a regulamentar os artigos da LDB sobre a educação profissional, a articulação entre o Ensino Médio e a Educação Profissional poderá ocorrer de forma:

1 - integrada, oferecida somente a quem já tenha concluído o ensino Fundamental [...]; 11 - concomitante, oferecida somente a quem já tenha concluído o ensino fundamental ou esteja cursando o ensino médio [...] podendo ocorrer: a) na mesma instituição de ensino, aproveitando-se as oportunidades educacionais disponíveis; b) em instituições de ensino distintas, aproveitando-se as oportunidades educacionais disponíveis; ou c) em instituições de ensino distintas [...];

111 - subsequente, oferecida somente a quem já tenha concluído o ensino médio (Brasil, 2004).

É importante destacar que, em 2007, o número de matrículas nesse tipo de educação sofreu uma diminuição de $6,9 \%$, o que representa 51.080 matrículas a menos.

Considerando os dados censitários e o documento produzido pelo INEP (2006a), é possível perceber que as redes estaduais vêm mostrando um interesse maior pela articulação entre a Educação Profissional e o Ensino Médio, mas essa 
oferta é ainda bastante diminuta. De acordo com os dados do Censo da Educação Básica de 2007, apenas 0,5\% das matrículas do Ensino Médio estavam articuladas à Educação Profissional.

De acordo esse documento do INEP, em 2005 - um ano após o Decreto 5154/2004 -, das 659 escolas estaduais que ofertavam a Educação Profissional, 19\% a ofertavam integrada ao Ensino Médio. Esse número é bem superior ao apresentado pela rede privada, pois das 2350 instituições que ministravam esse tipo de educação de nível técnico, apenas 4,4\% realizavam essa oferta de forma integrada. Em 2007, apenas 3,9\% da oferta da Educação Profissional privada de nível técnico ocorreu de forma integrada ao Ensino Médio, enquanto a rede estadual alcançou o percentual de 15\%. Essas diferenças expressam bem a postura da iniciativa privada e a diferença dos seus interesses daqueles que têm como referência a oferta pública de ensino e um modelo de educação profissional que não seja aquele voltado apenas para a confecção de sujeitos atentos aos interesses do mercado de trabalho.

A revogação do decreto 2208/97 sempre foi um dos objetivos dos setores da sociedade civil comprometidos com os interesses das escolas públicas e críticos ao modelo de Educação Profissional e de Educação Básica impostos no governo Fernando Henrique Cardoso. Nesse sentido, a revogação desse decreto abriu a possibilidade de avançar na construção de um modelo de Educação Profissional e de Ensino Médio atento aos interesses dos setores oriundos da classe trabalhadora. Essa possibilidade parece aos poucos ir efetivando-se na oferta de Ensino Médio de forma integrada à Educação Profissional, embora não possamos deixar de destacar o fato de que há muito para se avançar nessa direção, sendo o financiamento uma questão de extrema prioridade.

\section{Os limites do financiamento público para a universalização do Ensino Médio Integrado}

Mesmo que não tivéssemos acesso aos dados referentes ao financiamento da educação brasileira, não seria difícil chegar à conclusão que se gasta muito pouco.

Escolas sucateadas, professores mal pagos e em número insuficiente, ausência de bibliotecas, déficit no número de carteiras, problemas com iluminação, falta de água potável, infraestrutura precária etc. são alguns dos diversos problemas que enfrentam as escolas públicas brasileiras e que levam os alunos a chegarem ao final da Educação Básica em condições extremamente deficitárias no referente a disputar um emprego ou continuarem seus estudos.

Tendo como referência os dados do INEP, Carreira e Pinto (2007) assim sintetizam o quadro problemático da infraestrutura das escolas brasileiras:

Quanto aos recursos de infraestrutura e equipamentos, a situação é crítica em todos os níveis da educação básica. Na educação infantil, destaca-se a falta de parques infantis e de sanitários adequados à idade das crianças. Nos ensino fundamental e médio, a carência de bibliotecas, laboratórios de ciências e de informática. Cabe ainda ressaltar que não há pessoal qualificado para a função na quase totalidade das escolas que declaram possuir bibliotecas. A existência de pontos de internet é insignificante no ensino fundamental e muito abaixo do desejável nas escolas de ensino médio (p. 37)

Dados do Exame Nacional do Ensino Médio - ENEM - evidenciam as disparidades de rendimentos entre os estudantes das escolas públicas estaduais e os estudantes das escolas privadas.

Diante desse quadro, constata-se estarmos na direção contrária do discurso generalizado, o qual destaca como fundamental uma Educação Básica capaz de garantir os conhecimentos necessários ao novo momento do processo de produção de mercadorias e de globalização econômica (CEPAL/UNESCO, 1992). Ou seja, assistimos escolas incapazes de garantir aos alunos um processo de aprendizagem condizente com o momento atual. 
A submissão/cumplicidade das nossas elites ao capital internacional tem levado a que as políticas sociais, particularmente a educação, seja colocada em segundo plano, fazendo jus às palavras de Marcos Arruda (1999), quando este afirma que o envio contínuo de divisas para o estrangeiro objetivando garantir o pagamento da dívida externa leva a que possamos dizer que "para o capital, tudo; para o social, migalhas".

Essa interpretação pode ser reforçada quando observamos que embora os governantes brasileiros mostrem-se preocupados com a problemática social, as despesas brasileiras na área social são muito tímidas comparadas às efetivadas para saudar os débitos com credores externos e internos.

Comparando-se os gastos do governo federal com Educação aos efetivados para saudar a dívida externa (Tabela 2), entende-se o motivo pelo qual a crise na Educação agudiza-se, sem que possamos ter a certeza de que estamos nos livrando do fardo de uma dívida que se mostra eterna.

Os dados apresentados nessa tabela embora façam referência a períodos que compreendem mandatos de presidentes distintos: Lula da Silva (2003-2005) e Fernando Henrique Cardoso (1997-2002) - evidenciam o fato de que a mudança presidencial não causou uma modificação da postura governamental em relação ao sacrifico das ações sociais em benefício do cumprimento das obrigações com o pagamento da dívida externa. Talvez seja mais correto argumentar que a posição de sacrifício social que foram postos aos países da América Latina para garantir os interesses do capital internacional, via pagamento da divida da externa ou abertura da economia ao capital internacional (Bandeira, 2002, Chossudovsky, 1999), decorre do acatamento desses líderes políticos ao conjunto de reformas políticas e econômicas, comumente chamadas de neoliberais.

Considerando todos os países da América Latina, inclusive o Brasil, não é possível deixar de fazer referência que foi fato visivel o quanto essas nações, em velocidades distintas, mas sem grandes questionamentos das suas elites, pouco a pouco foram estabelecendo modificações nas agendas estatais, objetivando atender aos preceitos estabelecidos pelos arquitetos da dominação norte-americana sobre as nações mais pobres, o chamado Consenso de Washington (Portella Filho, 1994, Bandeira, 2002).

Esse "consenso", entre outras determinações, apontava para a mudança nas prioridades do gasto público. 0 que quer dizer, para um bom entendedor e para os governantes subordinados, acatar a determinação do grande capital e do Tio Sam: reduzir os gastos nas áreas sociais.

Ainda quando se analisa a Tabela 2, chega-se à conclusão que não existe apenas um processo de dilapidação do patrimônio público, visando garantir o pagamento dessa dívida, mas também se presencia, em virtude da sangria financeira, o impedimento de construção do novo.

Tabela 2: Dados sobre o serviço da dívida externa brasileira e o orçamento do Ministério da Educação (em bilhões).

\begin{tabular}{|l|c|c|c|c|c|c|}
\hline & \multicolumn{2}{|c|}{$\begin{array}{c}\text { Juros pagos da } \\
\text { dívida externa (A) }\end{array}$} & \multicolumn{2}{c|}{$\begin{array}{c}\text { Amortização da } \\
\text { dívida externa (B) }\end{array}$} & $\begin{array}{c}\text { Total } \\
\text { pago } \\
\text { A + B }\end{array}$ & $\begin{array}{c}\text { Orçamento do } \\
\text { Ministério da } \\
\text { Educação }\end{array}$ \\
\hline Ano & US\$ & R $\$$ & US\$ & R \$ & R\$ & R\$ \\
\hline 1997 & 14.410 & 15.995 & 26.021 & 28.883 & 44.878 & 7.269 \\
\hline 1999 & 17.468 & 31.268 & 52.907 & 94.704 & 125.972 & 8.737 \\
\hline 2000 & 17.096 & 33.337 & 34.989 & 68.229 & 101.566 & 10.606 \\
\hline 2001 & 17.621 & 40.881 & 33.000 & 76.560 & 117.441 & 11.647 \\
\hline 2002 & 14.216 & 50.182 & 35.677 & 125.940 & 176.122 & 13.220 \\
\hline 2003 & 14.179 & 40.977 & 38.809 & 112.158 & 153.135 & 14.229 \\
\hline 2004 & 14.282 & 37.847 & 37.623 & 99.701 & 137.548 & 13.835 \\
\hline 2005 & 14.519 & 33.974 & 51.715 & 121.013 & 154.987 & 15.409 \\
\hline
\end{tabular}

Os dados da dívida externa brasileira estão apresentados nos relatórios do Banco Central em Dólar Americano (US\$). Para conversão em Real (R\$), utilizamos a taxa cambial do último dia útil de cada ano.

Fonte: Elaboração própria a partir de Boletins do Banco Central - relatórios anuais. Disponíveis em <www.bcb.org.br $>$. 
Há um movimento contínuo de elevação de recursos destinados ao pagamento da dívida e eles são, cada vez mais, extremamente superiores aos destinados ao Ministério da Educação.

Em muitos momentos, o investimento para saldar os débitos com a dívida externa (juros e amortizações) chega a ser dez vezes maior que o orçamento do Ministério da Educação. Sobre esse fato, Romão (1995) fez a seguinte constatação:

Aparentemente, não existe relação entre o baixo desempenho dos sistemas educacionais e a dívida externa. No entanto, o caso do Brasil é emblemático: no Ano Internacional da Alfabetização (1990), somente o serviço da dívida externa brasileira equivaleu aproximadamente ao triplo de tudo que se aplicou no ensino fundamental público no país. Por outro lado, tem sido demonstrada, à exaustão a queda de investimentos na prestação de serviços sociais, particularmente nos sistemas educativos dos países endividados... (p. 91)

Se esse alerta pode ser considerado de longa data e desatualizado, não podemos deixar de fazer referência ao trabalho de Eduardo Baldijão (199-), demonstrando os cortes orçamentários realizados durante o governo Fernando Henrique
Cardoso e que atingiram diretamente o orçamento do Ministério da Educação, em 1995, de forma a atender aos interesses de credores internacionais.

Essas duas referências (Baldijão e Romão), entre muitas, evidenciam como a Educação foi e é tratada de forma secundária, quando é posta diante dos interesses de credores nacionais e internacionais. A título de exemplo, o próprio Eustáquio Romão (1995) destaca que, na década de 1990, dos 21 países latino-americanos, apenas 50\% aumentaram a aplicação dos recursos em relação ao PIB; em 9 países, o gasto em Educação ocupou um maior espaço no dispêndio governamental; e somente em 8 países, o gasto per capita anual no ensino primário elevou-se.

Se considerarmos que há o crescimento da dívida bem como dos recursos destinados ao seu pagamento, sem que haja paralelamente um crescimento maior da riqueza produzida em nosso país - Produto Interno Bruto, PIB (Tabela 3) -, evidencia-se que não estamos distante de inviabilizarmos qualquer projeto social que pressuponha a ampliação do investimento do poder público.

Conforme a Tabela 3, além do crescimento da dívida externa, apesar do aumento do pagamento de seus juros e dos valores das amortizações, presenciamos um aumento contínuo da dívida pública em relação ao nosso

Tabela 3: Evoluções da dívida externa, PIB brasileiro e a relação entre a dívida pública e o PIB brasileiro (em bilhões).

\begin{tabular}{|c|c|c|c|c|}
\hline Ano & \multicolumn{2}{|c|}{ Dívida externa } & PIB & $\begin{array}{c}\text { Percentual da dívida } \\
\text { pública em relação ao } \\
\text { PIB }\end{array}$ \\
\hline & US\$ & R\$ & US\$ & \\
\hline 1995 & 159.256 & 154.478 & 705.449 & 31,1 \\
\hline 1996 & 179.935 & 186.772 & 775.475 & 30,11 \\
\hline 1997 & 199.998 & 221.998 & 807.814 & 33,4 \\
\hline 1998 & 241.644 & 292.389 & 787.889 & 37,8 \\
\hline 1999 & 239.855 & 429.340 & 536.554 & 50,4 \\
\hline 2000 & 236.157 & 354.236 & 602.207 & 49,6 \\
\hline 2001 & 225.835 & 523.937 & 509.797 & 52,0 \\
\hline 2002 & 210.711 & 743.809 & 459.379 & 57,3 \\
\hline 2003 & 214.930 & 621.147 & 506.784 & 56,6 \\
\hline 2004 & 201.374 & 533.641 & 603.994 & 54,9 \\
\hline 2005 & 169.450 & 396.513 & 796.284 & 51,2 \\
\hline
\end{tabular}

"Dados extraídos do Anuário Estatístico 2006, disponível no site do Ministério do Desenvolvimento Indústria e Exterior: www.desenvolvimento.gov.br.

Fonte: Elaboração própria a partir de Boletins do Banco Central - relatórios anuais. Disponíveis em <www.bcb.org.br $>$. 


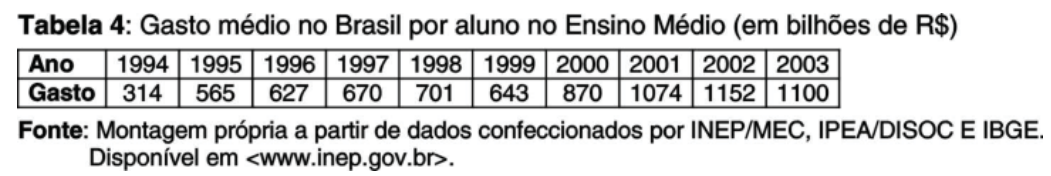

PIB. Embora tenha sido largamente divulgado pelo Presidente Lula a diminuição da nossa dívida externa, creio ser necessário destacar uma observação feita por Fernando Reimers (1995) sobre a impertinência de se pensar crescimento econômico, subordinando-se aos imperativos de evasão de divisas.

Os governos têm que implementar programa de ajustamento, voluntariamente ou sob pressão das agências financiadoras internacionais, a fim de receber mais empréstimos. 0 gerenciamento da divida externa na década passada enfatizou o pagamento desta: o foco era a elevação dos ganhos no exterior para continuar atendendo ao serviço da dívida. Um efeito colateral dessa visão de curso prazo foi o negligenciamento dos níveis de investimento e produção, compressão do consumo interno e dos salários e, em muitos casos, financiamentos dos orçamentos governamentais por mecanismos inflacionários. 0 resultado claro dessa política foi que a maior parte da América Latina não conheceu qualquer crescimento nos anos 1980. (p. 17)

É preocupante pensar que as modificações necessárias à Educação, bem como a todas as áreas sociais, dependam de uma maior intervenção do governo federal. 0 Ensino Médio, apesar de estar quase sob total controle das redes estaduais de ensino, não conseguirá efetivar um processo de crescimento com qualidade se não houver uma modificação do papel do governo federal em relação ao seu financiamento.

Discutir os dados referentes ao custo de um aluno do Ensino Médio no Brasil, obriganos a lembrar que temos uma variação muito grande quando comparamos os gastos da redes públicas estaduais e federal e, muitas vezes, no interior da rede federal, há variações no valor gasto por aluno de acordo com o porte e a localidade da instituição ${ }^{4}$. De qualquer forma, é fato notório que o gasto por aluno das instituições federais é muito maior do que o das escolas estaduais.

0 valor por aluno das instituições federais chegou a ser - nos anos de 1994, 1997 e 1998 - oito vezes maior que o valor dos alunos das redes estaduais. Além disso, recentemente, quando pesquisamos os relatórios de prestação de contas de várias instituições federais, pudemos constatar que o valor por aluno dessas instituições nunca é inferior a quatro mil reais.

De posse dessas informações, é possível constatar o quanto o gasto médio (majoritariamente de alunos das redes estaduais) de aluno do Ensino Médio no Brasil se distancia do custo de um estudante da rede federal de ensino (Tabela 4), evidenciando-se o fato de que, no Brasil, confirmado nos dados do ENEM, as redes estaduais são aquelas que, por terem o menor gasto por aluno, apresentam os piores desempenhos.

Entretanto, não aceitamos a argumentação de que o valor por aluno da esfera federal seja alto. Essa argumentação em articulação com outra, que dizia que os CEFETS e as escolas agrotécnicas federais só têm sentido de existirem se a formação que ministram estiver encaminhando os alunos ao mercado de trabalho, foram pilares para as reformas ocorridas no governo Fernando Cardoso, extremamente danosas ao Ensino Médio e à Educação Profissional em nosso país (Cordeiro, 2004).

Nossa posição é de cobrança para que sejam aumentados os recursos destinados à manutenção e ao pagamento de professores dos sistemas estaduais de ensino, de forma que pos-

4. Essa constatação decorre das informações referentes ao valor gasto por aluno que levantamos em diversas instituições da rede federal de ensino tecnológico. 
samos democratizar, para a maioria da população, a qualidade de um sistema de ensino que, embora tenha sofrido com as políticas de sucateamento do governo federal, mantém-se ainda como expressão de uma escola de boa qualidade.

Uma escola de qualidade demanda investimentos suficientes ao pagamento de bons salários aos profissionais da Educação; à manutenção de bibliotecas, laboratórios, áreas de esportes; atividades culturais das mais diversas; e tudo mais que é demandado num processo educativo orientado à formação do ser humano na sua integralidade (Zibas, 1993).

Especificamente sobre o EMI, além das preocupações acima citadas, não se pode esquecer que pela peculiaridade da integração entre a formação profissional e a formação geral deve-se dar muita atenção ao financiamento de ações voltadas a uma contínua capacitação dos professores para que possam desenvolver suas atividades a contento. Como pôde ser constatado no seminário nacional de educação profissional "Educação Profissional: concepções, experiências, problemas e propostas" (BRASIL/MEC/SEMTEC, 2003), há muitas insatisfações do professorado que dizem respeito às condições de trabalho na Educação Profissional. Problemas como a necessidade de uma melhoria da qualificação, visando atender aos novos requisitos da legislação em vigor; a dificuldade de inserção em cursos de pós-graduação; a precarização da profissão docente; a debilidade dos cursos de licenciatura para a preparação dos docentes da Educação Profissional; a existência de um quadro significativo de professores não possuidores de uma certificação de Ensino Superior etc. são alguns dos muitos itens merecedores de uma atenção especial do Ministério da Educação e das se- cretarias estaduais de educação, que só podem ser enfrentados se, de fato, houver um comprometimento de enfrentar essas dificuldades, aumentando os recursos disponíveis para o financiamento não só do Ensino Médio, mas de toda a Educação Básica.

Para que se consiga aumentar os investimentos para o Ensino Médio, há necessidade de uma mudança radical na postura do governo federal no concernente à sua participação no financiamento desse nível de ensino.

Se, como mostramos anteriormente, o orçamento do Ministério da Educação é extremante diminuto, comparando-o aos destinados para garantir os serviços da dívida externa, menos aceitável é o quanto se destina para o financiamento do Ensino Médio. De acordo com os dados levantados (Tabela 5), a participação do governo federal, além de ser pequena, é extremamente oscilante, evidenciando que, no concernente a esse nível de ensino, o governo tem se comprometido precariamente com a manutenção da rede federal de ensino tecnológico. Ou seja, se no governo Fernando Henrique Cardoso foi evidente o descompromisso com o financiamento do Ensino Médio, no atual governo, esse nível ainda não se configurou como assunto prioritário, mesmo ele se esforçando em mostrar que objetiva garantir uma maior entrada de estudantes das escolas públicas no Ensino Superior, via Programa Universidade para Todos - PROUNI.

Não faz parte da agenda do governo federal garantir a ampliação da oferta de Ensino Médio em articulação com a melhoria da qualidade do ensino. 0 máximo da ação do poder central no sentido de ampliar sua participação no financiamento desse nível de ensino foi a aprovação do Fundo de Manutenção e Desenvolvimento da Educação Básica e de Valorização dos

Tabela 5: Gasto médio no Brasil com o Ensino Médio x a participação da união no financiamento
(em R\$ milhões).
\begin{tabular}{|l|c|c|c|c|c|c|c|c|c|c|c|}
\hline Ano & 1994 & 1995 & 1996 & 1997 & 1998 & 1999 & 2000 & 2001 & 2002 & 2003 & 2004 \\
\hline Geral & 1.263 & 2.378 & 3.015 & 3.656 & 4.310 & 4.595 & 5.506 & 5.994 & 3.550 & 3.878 & 6.724 \\
\hline Estados & 1.005 & 2.001 & 2.626 & 2.847 & 3.554 & 4.075 & 5260 & 5432 & 2890 & 3.742 & 6.612 \\
\hline União & 172 & 196 & 176 & 504 & 509 & 275 & 246 & 562 & 660 & 135 & 112 \\
\hline
\end{tabular}
Os dados referentes aos anos de 2003 e 2004 foram encontrados no site do INEP: www.inep.gov.br.
gasto geral e o gasto do governo federal.
Fonte: SIAFI-MF/STN disponível no site no Ministério da Fazenda: www.tesouro.fazenda.gov.br.


Profissionais da Educação - FUNDEB. Para nós, esse fato não atende ao requisitado como mudança da postura do governo federal.

Entendemos que o FUNDEB não consegue atender às necessidades do Ensino Médio, principalmente quando integrado à educação profissional, pelo fato de o valor por aluno (ao articularmos formação profissional e formação geral) ser muito mais elevado (INEP, 2006b). Nesse sentido, as quase oito milhões de matrículas das redes estaduais não serão atendidas com melhor qualidade em virtude, apenas, de um acréscimo pouco expressivo de investimentos do governo federal nos próximos anos, ainda que saibamos que os recursos dos estados para a Educação Básica serão aumentados.

Os recursos adicionais do governo federal que compõem o FUNDEB serão direcionados a toda Educação Básica e deverá alcançar o valor de 5 bilhões de reais somente em 2010 (Pernambuco, 2007). Não é difícil imaginar o quanto esse montante é pequeno se objetivarmos o valor por aluno do Ensino Médio de todas as escolas públicas próximo ao efetivado pelas escolas da rede federal. Em outras palavras, quase oito milhões de alunos a um valor de, pelo menos, quatro mil reais significaria no momento atual, apenas para o Ensino Médio, um incremento de despesas para o governo federal superior a 20 bilhões de reais. Daí, afirmarmos o quanto o FUNDEB está longe de efetivar os avanços para o Ensino Médio que aqui reclamamos.
Enfatizamos a necessidade de o governo federal ampliar sua participação no financiamento do Ensino Médio, não para isentarmos os governos estaduais desses gastos e do compromisso de aumentarem o financiamento, mas em virtude de a escola que almejamos dificilmente poder ser implementada se for mantida inadvertidamente a rigorosa divisão de responsabilidade que está posta na lei.

Sabemos que, constitucionalmente, cabe aos estados e ao distrito federal a obrigação de aplicar 25\% da suas receitas com a Educação após serem feitas as transferências devidas. Sabemos também que após a criação do FUNDEF em 1996, 60\% desse montante foi diretamente aplicado exclusivamente no Ensino Fundamental. Ou seja, de 1997 a 2006, os estados reservaram no máximo 40\% do que arrecadaram para investir no Ensino Médio e no Superior e também no próprio Ensino Fundamental.

Mesmo com a criação do FUNDEB, não deixará de existir por parte dos estados um limite na sua capacidade de financiamento do Ensino Médio. Não só pelo compromisso que eles têm com toda a Educação Básica, mas também com a manutenção da oferta de Ensino Superior.

De acordo com os dados do censo do Ensino Superior de vários anos (Tabela 6), observamos que embora não seja de responsabilidade legal dos estados a sua manutenção, essa oferta se mantém presente e em processo de crescimento.

Tabela 6: Número de matrículas, de docentes e de funcionários nas instituições estaduais de ensino superior

\begin{tabular}{|c|c|c|c|c|}
\hline Ano & Matrículas & Instituições & Funcionários & Docentes \\
\hline 1992 & 210.133 & 82 & 24.554 & - \\
\hline 1993 & 216.535 & 77 & 23.963 & - \\
\hline 1994 & 231.936 & 73 & 25.239 & - \\
\hline 1995 & 239.215 & 76 & 25.932 & - \\
\hline 1996 & 243.101 & 74 & 26.064 & - \\
\hline 1997 & 253.678 & 74 & 27.714 & 55.947 \\
\hline 1998 & 274.934 & 74 & 30.621 & 47.119 \\
\hline 1999 & 302.380 & 72 & 29.141 & 45.705 \\
\hline 2000 & 332.104 & 61 & 33.730 & 45.479 \\
\hline 2001 & 357.015 & 63 & 34.618 & 42.629 \\
\hline 2002 & 415.569 & 65 & 35.354 & 42.057 \\
\hline 2003 & 442.706 & 65 & 36.098 & 42.764 \\
\hline 2004 & 471.661 & 75 & 38.182 & 46.162 \\
\hline 2005 & 477.349 & 75 & 39.780 & 44.718 \\
\hline
\end{tabular}

Fonte: Montagem própria a partir do Censo Escolar - diversos anos. Disponível em< www.inep.gov.br>. 
Considerando o que está apresentado nessa tabela, acreditamos que os desafios postos para as redes estaduais de ensino no referente ao financiamento do Ensino Médio não são poucos. A sua oferta de Ensino Superior deve ser analisada levando em consideração a existência de um número crescente de egressos do Ensino Médio.

Se considerarmos que o valor por aluno no Ensino Superior, de acordo com levantamento feito pelo INEP em 2000, é aproximadamente dez vezes maior que no Ensino Médio, podemos afirmar que as redes estaduais, ao manterem o Ensino Superior, estariam se responsabilizando também por cerca de 4,7 milhões de alunos do Ensino Médio. Esse número não é nada desprezível se lembrarmos que ele representa mais da metade das matrículas no Ensino Médio efetuadas pelas redes estaduais em 2006.

Nossa observação torna-se, no momento atual, de extrema importância, pois temos a preocupação que poderá haver por parte dos estados certo descompromisso com o Ensino Médio em função da implantação do FUNDEB. Eles poderão simplesmente responder à sociedade, quando esta cobrar por maiores investimentos, que ao aderirem ao FUNDEB estão cumprindo com suas responsabilidades legais, não tendo porque haver a exigência de maiores investimentos.

Temos plena convicção de que o movimento de afirmação do Ensino Médio integrado decorre de uma modificação do seu financiamento. Manter as mesmas estratégias até agora utilizadas pelo poder público é apostar na derrota de uma concepção político-pedagógica que aponta na perspectiva da emancipação daqueles que vivem do trabalho.

\section{Considerações finais}

A realidade que hoje vivenciamos no Brasil denota a grande dificuldade para se edificar um projeto de EMI que seja capaz de não só formar os educandos para uma futura inserção no mercado de trabalho, mas princi- palmente ter uma intervenção social e política mais criativa e autônoma.

Tal estado de coisas evidencia que, aliado à manutenção da dicotomia educacional brasileira entre a formação profissional e a formação geral, vivenciamos a trágica situação de não termos uma política de financiamento para o Ensino Médio que objetive assegurar uma formação coerente com as exigências da atual realidade.

Estamos muito longe de concretizarmos um projeto educativo no qual a formação integral dos educandos esteja posta como prioridade. Nesse contexto, o EMI mostra-se incapaz de concretizar-se universalmente como um momento de transição para um projeto de educação de caráter politécnico.

Entretanto, como disse Gramsci (apud Frigotto, 2005), a escola só sofre mudanças realmente quando se torna problema e projeto efetivo de uma sociedade. Esperamos que os debates sobre o financiamento da Educação Básica, bem como sobre a construção de um projeto político pedagógico para o Ensino Médio ultrapassem os muros das escolas, das secretarias de educação e da academia e passem também a fazer parte da agenda de outros espaços da sociedade, principalmente daqueles que sejam expressões de organização dos trabalhadores, de forma que num futuro não muito distante possamos vivenciar uma nova realidade, na qual exista uma maior possibilidade de uma escola que seja expressão das classes que vivem do trabalho.

A luta por um EMl e de qualidade - e, por conseguinte, pelo seu financiamento decorre do fato de que não acreditamos que a luta por uma nova sociedade possa deixar de levar em consideração a importância da escola na formação de novos atores sociais.

Por mais que enxerguemos o papel que o capital reserva para a educação escolar - seja utilizando a escola como instrumento de formação de mentalidades submissas e atreladas aos seus interesses ou mesmo utilizando a educação escolar como mercadoria (Hill, 2003) -, contraditoriamente, a escola pode ser uma 
aliada na formação de sujeitos comprometidos com uma nova realidade social.

A educação é uma instituição necessária para incorporar a população a todo tipo de transformação social, efetiva, que se pretenda. Se, como é sobejamente conhecido, a educação é incapaz de mudar a sociedade desigual em que vivemos, ela é um recurso relevante para a compreensão dos fundamentos da desigualdade e para a geração de uma nova institucionalidade no país. (Ciavatta, 2005, p. 102)

Nesse sentido, não podemos esquecer que "não se superam as desigualdades no âmbito educativo e cultural sem, concomitantemente, superar a materialidade de relações sociais que as produzem” (Frigotto, 2005, p. 77). Assim, a luta não é só por outra política de financiamento para o Ensino Médio, mas para superar as causas que levam as atuais políticas a serem débeis à constituição de um Ensino Médio de melhor qualidade.

A defesa de um EMl de qualidade não está desarticulada da luta pela escola unitária e, por conseguinte, por uma sociedade socialista. Afinal, "a efetiva democratização da educação só será possível com a efetiva democratização da sociedade, em outro modo de produção, em que todos os bens materiais e culturais estejam disponíveis a todos os cidadãos" (Kuenzer, 2002, p. 33). Por isso, a concretização desse projeto demanda a urgência da vontade e da prática das classes que vivem do trabalho, não só na perspectiva da constituição de outro projeto educacional, mas principalmente o desenvolvimento de práticas voltadas para a organização de outro projeto de sociedade.

\section{Referências bibliográficas}

ARRUDA, M. Dívida e(x)terna: para o capital, tudo; para o social, migalhas: Petrópolis: Vozes, 1999.

BALDIJÃO, C. E. Orçamento Geral da União. [199-]. Disponível em < http://www.pt.org.br/assessor/orced.htm>. Acessado em 20/04/ 2008.

BRASIL. Decreto n. 5154, de 23 de Julho de 2004. Regulamenta $0 \S 2^{\circ}$ do art. 36 e os arts. 39 a 41 da Lei $n^{\circ} 9.394$, de 20 de dezembro de 1996, que estabelece as diretrizes e bases da educação nacional, e dá outras providências. Diário Oficial da União, Brasília, 23 jul. 2004

. MEC. SEMTEC. Seminário nacional de educação profissional: concepções, experiências, problemas e propostas. Anais, Brasilia, 16 a 18 de junho de 2003.

BANDEIRA, L. A. As políticas neoliberais e a crise na América do Sul. Revista Brasileira de Política Internacional, v. 45, n. 2, p. 135-146, 2002.

CARREIRA, D.; PINTO, J. M. R. Custo aluno-qualidade inicial: rumo à educação pública de qualidade no Brasil. São Paulo: Global; Campanha Nacional pelo Direito à Educação, 2007.

CEPAL/UNESCO. Educación y conocimiento: eje de la transformación productiva con equidad. Santiago de Chile, 1992.

CHOSSUDOVSKY, M. A globalização da pobreza: impactos das reformas do FMI e do Banco Mundial. São Paulo: Moderna, 1999.

CIAVATTA, M. A formação integrada: a escola e o trabalho como lugares de memória e de identidade In: FRIGOTTO, G. et al. (Orgs.). Ensino médio integrado: concepções e contradições. São Paulo: Cortez, 2005. p. 83-105.

CORDEIRO, E. de P. A reforma da educação profissional dos anos 90 no Centro Federal de Educação Tecnológica de Pernambuco (CEFETPE). 2004. 292 f. Dissertação (Mestrado em Educação)- Universidade Federal de Pernambuco, Recife, 2004. 
CUNHA, L. A. As agências financeiras internacionais e a reforma brasileira do Ensino Técnico: a crítica da crítica In.: ZIBAS, D. M. L. et al. (Orgs.). 0 ensino médio e a reforma da educação básica. Brasília: Plano, 2002. p. 103-134.

FRIGOTTO, G. Concepções e mudanças no mundo do trabalho e o Ensino Médio. In: FRIGOTTO, G. et al. (Orgs.). Ensino médio integrado: concepções e contradições. São Paulo: Cortez, 2005. p. 57-82.

FRIGOTTO, G.; CIAVATTA, M. A formação do cidadão produtivo: a cultura de mercado no ensino médio técnico. Brasília: INEP, 2006.

FRIGOTTO, G., CIAVATTA, M.; RAMOS, M. A gênese do Decreto n. 5154/2004: um debate no contexto controverso da democracia restrita. In: FRIGOTTO, G. et al. (Orgs.). Ensino médio integrado: concepções e contradições. São Paulo: Cortez, 2005. p. 2156.

FRIGOTTO, G. et al. (Orgs.) Ensino médio Integrado: concepções e contradições. São Paulo: Cortez, 2005.

HILL, D. 0 neoliberalismo global, a resistência e a deformação da educação. Currículo sem fronteiras, v. 3, n. 2, p. 25-59, jul./ dez. 2003.

INEP. Educação profissional técnica de nível médio no censo escolar. Brasília: INEP, 2006a.

Pesquisa nacional qualidade na educação. Brasília: INEP, 2006b.

KUENZER, A. Z. (Org.). Ensino médio: construindo uma proposta para os que vivem do trabalho. 3. ed. São Paulo: Cortez, 2002.

OLIVEIRA, R. de. Agências multilaterais e a educação profissional brasileira. Campinas: Alínea, 2006.

PERNAMBUCO. Cartilha do FUNDEB. Recife: Tribunal de Contas, 2007.

PORTELLA FILHO, P. 0 ajustamento na América Latina: crítica ao modelo de Washington. Lua Nova, São Paulo, n. 32, p. 101-132, 1994.

REIMERS, F. Educação para todos na América Latina no século XXI e o desafio do endividamento externo In: ROMÃO, J. E. (Org.). Dívida externa e educação para todos. Campinas: Papirus, 1995. p. 13-36.

ROMÃO, J. E. Dívida externa, educação e integração latino-america In: (Org.). Dívida externa e educação para todos. Campinas: Papirus, 1995. p. 77-130.

SINASEFE. Texto para discussão sobre a educação tecnológica. Brasília: SINASEFE, 2004.

ZIBAS, D. A função social do Ensino Médio na América Latina: é sempre possível o consenso? Cadernos de Pesquisa, n. 85, p. 26-32, mai. 1993.

Recebido em 11.04.08

Aprovado em 09.02.09

Ramon de Oliveira é professor adjunto do Departamento de Fundamentos Sócio-Filosóficos da Educação e do Programa de Pós-Graduação em Educação da UFPE. 